\title{
It's not just the mitral valve - abnormal motion of the whole aorto-mitral apparatus occurs in both overt and subclinical hypertrophic cardiomyopathy
}

\author{
Chinwe Obianyo ${ }^{1,2^{*}}$, Gaby Captur ${ }^{1,2}$, Petros Syrris ${ }^{1}$, Luis Lopes ${ }^{1,3}$, Vimal Patel ${ }^{1}$, Patricia Reant ${ }^{4}$, Mariana Mirabel ${ }^{5}$, \\ Charlotte Manisty $^{1,2}$, Paul Bassett ${ }^{2}$, Daniel Sado ${ }^{1,6}$, Phillippa Talmud ${ }^{1}$, Perry M Elliott ${ }^{1,2}$, James C Moon ${ }^{1,2}$
}

From 19th Annual SCMR Scientific Sessions

Los Angeles, CA, USA. 27-30 January 2016

\section{Background}

Mitral valve abnormalities are an important cause of patient morbidity in hypertrophic cardiomyopathy (HCM) contributing to left ventricular outflow tract obstruction (LVOTO). Anterior mitral valve leaflet (AMVL) elongation predisposes to LVOTO. CMR detects this in overt HCM and in sarcomere gene mutation carriers without left ventricular hypertrophy (G+LVH-). However, the geometry of the mitral valve, the subvalvular apparatus and the LVOT is more complex. The purpose of this study was analyse the whole aorto-mitral area (the aorto-mitral apparatus) and track its dynamic motion to explore mechanisms involved in LVOTO-predisposition in subclinical HCM.

\section{Methods}

CMR using a 1.5-tesla scanner (Avanto, Siemens) was performed on $35 \mathrm{G}+\mathrm{LVH}$ - patients without left atrial (LA) enlargement ( $31 \pm 14$ years, $34 \%$ male), 31 patients with a clinical diagnosis of $\mathrm{HCM}$ with preserved ejection fraction ( $47 \pm 12$ years, $61 \%$ male, all with pathogenic/ likely pathogenic sarcomere mutations $[\mathrm{G}+\mathrm{LVH}+])$, and 53 matched healthy volunteers ( $45 \%$ male, $42 \pm 14$ ). Direct assessment of the aortomitral apparatus was performed on the 3-chamber view acquired using a breathheld steady-state free precession sequence. Cines were interrogated frame-by-frame, semi-automatically using an in-house script developed for MATLAB ${ }^{\circledR}$. The motion tracking software interactively assigned, tracked and graphed, the dynamic excursion of 4 pre-defined aortomitral regions of interest (ROI) throughout one

${ }^{1}$ Institute of Cardiovascular Science, University College London, London, United Kingdom

Full list of author information is available at the end of the article cardiac cycle: $\mathrm{ROI}_{1}$ - hinge point of the posterior MVL; $\mathrm{ROI}_{2}$ - intertrigonal mitral annulus; $\mathrm{ROI}_{3}$ - tip of the AMVL; $\mathrm{ROI}_{4}$ - anterior aortic annulus (Fig. 1).

\section{Results}

Qualitative examination of normalized two-dimensional displacement-versus-time plots in $\mathrm{G}+\mathrm{LVH}$ - patients revealed subtle systolic anterior motion (SAM) of the intertrigonal mitral annulus and reduced longitudinal excursion compared to controls. Statistically significant differences were present for $\mathrm{ROI}_{1}(P=0.005), \mathrm{ROI}_{2}(P=$ $0.01)$ and $\mathrm{ROI}_{4}(P<0.0001$, Fig. 1$)$. In $\mathrm{G}+\mathrm{LVH}+$ patients, displacement-versus-time plots for all 4 ROIs differed significantly from those of controls resulting from a combination of SAM, diminished longitudinal excursion and blunted end-diastolic motion (Fig. 2): $\mathrm{ROI}_{1}(P=0.02), \mathrm{ROI}_{2}(P=0.007), \mathrm{ROI}_{3}(P<0.0001)$ and $\mathrm{ROI}_{4}(P<0.0001)$.

\section{Conclusions}

The AMVL is longer in preclinical HCM, but in addition, there are more widespread abnormalities of the aorto-mitral apparatus motion, including SAM of the mitral annulus before the development of LVH or LA enlargement. These data have the potential to improve our understanding of early phenotype development and LVOTO-predisposition in HCM.

\section{Authors' details}

${ }^{1}$ Institute of Cardiovascular Science, University College London, London, United Kingdom. ${ }^{2}$ Bart's Heart Centre and Centre for Biostatistics and Epidemiology, London, United Kingdom. ${ }^{3}$ Cardiovascular centre, University of Lisbon, Lisbon, Portugal. ${ }^{4}$ University of Bordeaux, CHU de Bordeaux, Bordeaux, France. ${ }^{5}$ Assistance Publique-Hôpitaux de Paris, Hôpital Européen 

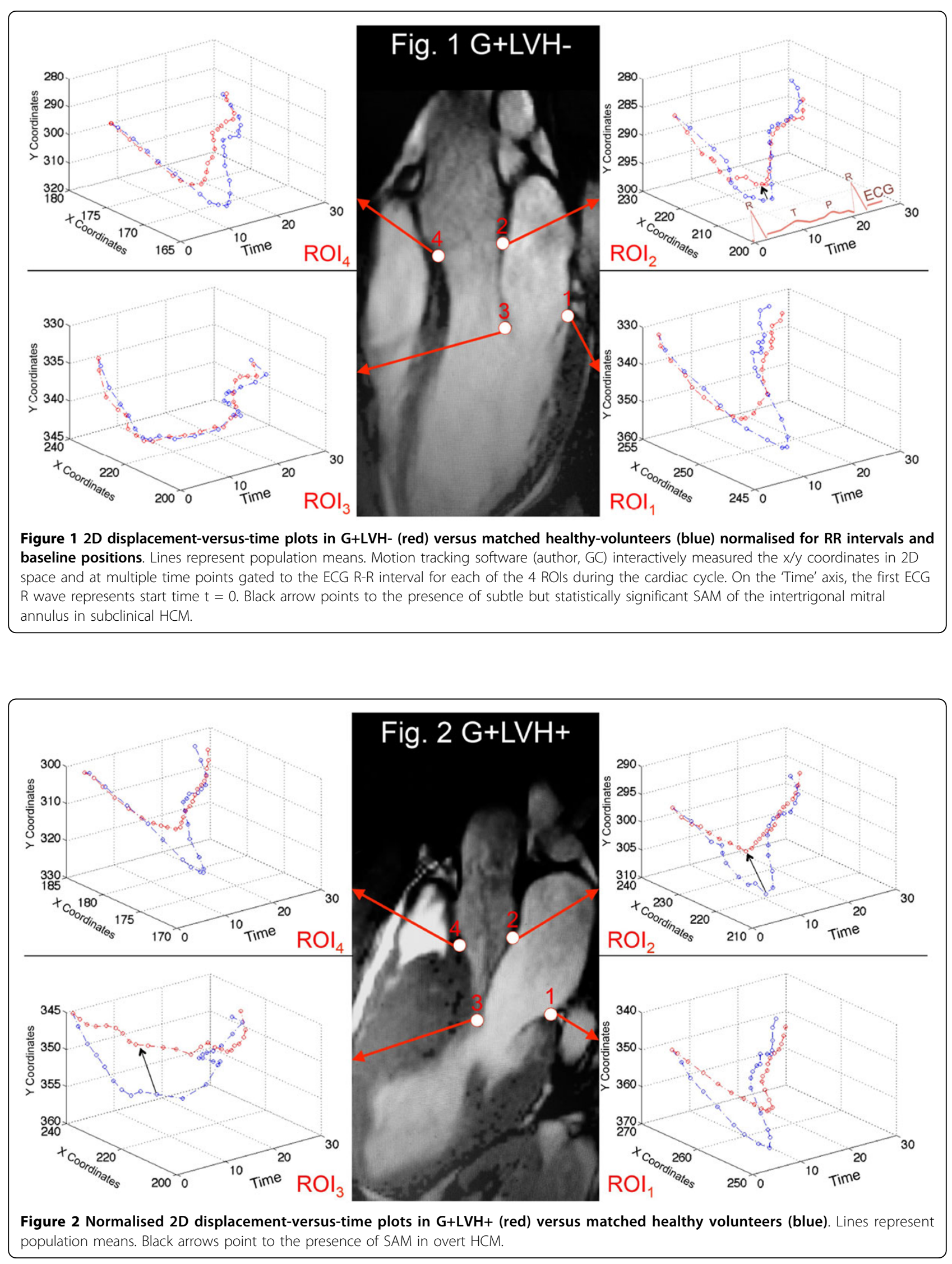
Georges Pompidou, Paris, France. ${ }^{6}$ Cardiology Department Kings College, London, United Kingdom..

Published: 27 January 2016

doi:10.1186/1532-429X-18-S1-Q37

Cite this article as: Obianyo et al:. It's not just the mitral valve - abnormal motion of the whole aorto-mitral apparatus occurs in both overt and subclinical hypertrophic cardiomyopathy. Journal of Cardiovascular Magnetic Resonance 2016 18(Suppl 1):Q37.

Submit your next manuscript to BioMed Central and take full advantage of:

- Convenient online submission

- Thorough peer review

- No space constraints or color figure charges

- Immediate publication on acceptance

- Inclusion in PubMed, CAS, Scopus and Google Scholar

- Research which is freely available for redistribution

Submit your manuscript at www.biomedcentral.com/submit

() Biomed Central 